\title{
Progress in the numerical modelling of dynamic testing for reinforcement and retaining elements used in underground excavations
}

JA Vallejos Department of Mining Engineering and Advanced Mining Technology Center, University of Chile, Chile

E Marambio Advanced Mining Technology Center, University of Chile, Chile

Y Marulanda Advanced Mining Technology Center, University of Chile, Chile

L Burgos Advanced Mining Technology Center, University of Chile, Chile

CV Gonzalez MIRARCO Mining Innovation, Canada

\begin{abstract}
In the last century the expansion of mining into high stress environments, where there are rockburst events caused by energy release, have become especially interesting for mining engineers in terms of geomechanics. These phenomena have prompted changes in conventional designs, implying more research into how underground excavations absorb dynamic impacts.
\end{abstract}

Testing programs carried out globally by recognised institutions have provided guidelines for the development of new support systems in the last 30 years. Therefore, new reinforcement elements and retaining elements capable of both resisting dynamic loads and yielding in the process without failing have been introduced in order to ensure safety of underground excavations. However, the integration of these elements under dynamic loads is a research area recently under development.

The execution of these testing programs implies a high cost in time and validation, hence a limited number of these have been completed. Numerical modelling to represent the performance of the dynamic process and enhance laboratory testing has become increasingly necessary and relevant.

This paper summarises improvements in the numerical modelling of dynamic testing, developed by the University of Chile and supported by MIRARCO (Mining Innovation Rehabilitation and Applied Research Corporation), for elements that constitute rock support used in underground excavations. An update of the numerical modelling of dynamic testing for threadbar used as rock reinforcement is presented. As well as the work carried out to date in the development of a numerical model of dynamic tests for a mesh used as a surface retaining element is illustrated.

Keywords: dynamic testing, reinforcement, retaining, numerical modelling, rockburst, high stress, underground mining

\section{Introduction}

New technological developments have been introduced in the mining industry within the last century. These technologies have responded not only to production and planning issues, but also to problems related to physical phenomena present in the field that hinder mining progress. Internationally, the number of rockburst events in high stress underground mining have increased in the last few years according to the rate of expansion in the depth of mining, prompting research into this phenomenon. Efforts to understand, quantify damage, and mitigate the effects of these events have increased due to studies carried out by recognised institutes within the mining industry, and based on the research performed by the Canadian Rockburst Research Program (Kaiser et al. 1996; Cai \& Kaiser 2018). 
Recently, the focus of study has been on how underground excavations are supported and how support systems absorb dynamic impacts. Therefore, research efforts have been studying the reinforcement and retainment elements that compose the support system in an attempt to improve the standard designs widely used and initially conceived for static load resistance. Research institutions such as the Canada Centre for Mineral and Energy Technology (CanMet) - Mining \& Mineral Sciences Laboratories (MMSL) of Canada; and the Western Australia School of Mines (WASM) have been studying the behaviour of reinforcement and retaining elements under dynamic loads. Their studies have evolved from simply comparing loads to analysing the capacity of support system elements to absorb energy from impacts and deform during the process. Through laboratory-scale testing representative of in situ conditions, the aforementioned institutions have worked to quantify the deformation and absorption of energy of these elements, resulting in comparative parameters and an adaptable design under dynamic loads.

However, laboratory-scale testing involves a high cost in preparation time and validation; hence a limited number of these tests are carried out. Numerical modelling is an alternative that, in addition to enhancing the results from laboratory testing, should be useful to explain the deformation and absorption process. Yi \& Kaiser (1994a), Tannant et al. (1995), Ansell (1999, 2005), Thompson et al. (2004), St-Pierre (2007) and Marambio et al. (2018) have modelled the dynamic behaviour of reinforcement elements in laboratory-scale testing centred around load-displacement relationships. The role of grout, however, has not been fully incorporated into these models even though the grout/rockbolt interface has been shown to be where the failure of most reinforcement elements occur in situ.

On the other hand, laboratory-scale testing for retaining elements is a research area that has been developed since the early 1980s. Ortlepp (1983), Pakalnis \& Ames (1983), Tannant et al. (1997), Thompson et al. (1999), Van Sint Jan \& Cavieres (2004), Roth et al. (2004), Dolinar (2006) and Player et al. (2008a) have performed laboratory-scale static testing programs of steel wire mesh. However, dynamic testing programs of retaining elements is an area in development in recent years, most likely Player et al. (2008a) at WASM were the first to perform this category of tests, and this still continues today. More recently, Brändle et al. (2017) began research on how excavation support (interaction between reinforcement elements and retaining elements) resists dynamic loads through a laboratory-scale dynamic testing facility specially designed for this purpose.

For its part, numerical modelling of static testing for retaining elements has been performed previously by Morton et al. (2007) and Karampinos et al. (2018), approaching its behaviour through the numerical analysis of its components. Nevertheless, the numerical modelling of the dynamic response of retaining elements is an area still in development, the work performed by Thoeni et al. (2013) was probably the first to expose the behaviour of steel wire meshes under dynamic loads through discrete modelling.

The process of developing a new laboratory-scale dynamic testing facility in Chile, supported by the University of Chile and MIRARCO (Mining Innovation Rehabilitation and Applied Research Corporation), used a mechanism similar to the CanMet-MMSL. It has conducted several studies in which numerical modelling is taken into account as an important part of the process. Here the methodology proposed to numerically model the process of laboratory-scale dynamic testing of reinforcement elements (Marambio et al. 2018) is summarised. Also, improvements in the development of the numerical modelling of an explicit reinforcement element are illustrated. Complementing, the work carried out to date in the development of a numerical model of dynamic test for a mesh used as surface retaining element is presented.

Based on the finite difference method, models of reinforcement elements with a specific focus on the threadbar (also known as rebar or gewibar) are developed, which is widely used as rock reinforcement in Chilean underground mining and globally. For its part, a welded wire mesh is implemented in the modelling of retaining elements due to its general use in underground mining. 


\section{Summary of numerical modelling of dynamic testing for reinforcement elements}

Currently, there are two laboratory testing facilities of dynamic conditions for rock reinforcement recognised by the industry. The first started between 1992 and 1994 by Yi \& Kaiser under the Canadian Rockburst Research Program (CanMet-MMSL facility), and the second was started in 2004 by Player \& Thompson with the support of the Minerals \& Research Institute of Western Australia (WASM facility). The difference between the CanMet-MMSL and the WASM dynamic testing facilities lie in the principle used for their experimental tests.

The CanMet-MMSL facility applies the energy transfer principle, whereas the WASM facility applies the momentum transfer concept. In this sense, the CanMet-MMSL facility transforms potential energy into kinetic energy through the fall of a mass from a given height that impacts the lower end of a rockbolt embedded in a pipe with grout causing deformation and possible failure (simulating the in situ conditions). On the other hand, the WASM dynamic facility operates by measuring the effects of the fall of a complete system including a beam, the reinforcement, and a loading mass. The system falls freely until a point where it is abruptly stopped by buffers. Under this condition, the rockbolt continues to move and could lengthen and/or slip and possibly fail.

The Dynamic Impact Tester facility of New Concept Mining (Crompton et al. 2018) applies the same principle as CanMet-MMSL, expanding the catalogue of laboratory-scale dynamic testing facilities with new configurations of tests and reinforcement elements. Figure 1a shows the CanMet-MMSL dynamic testing facility set-up, while Figure $1 \mathrm{~b}$ shows the dynamic testing facility developed by WASM.

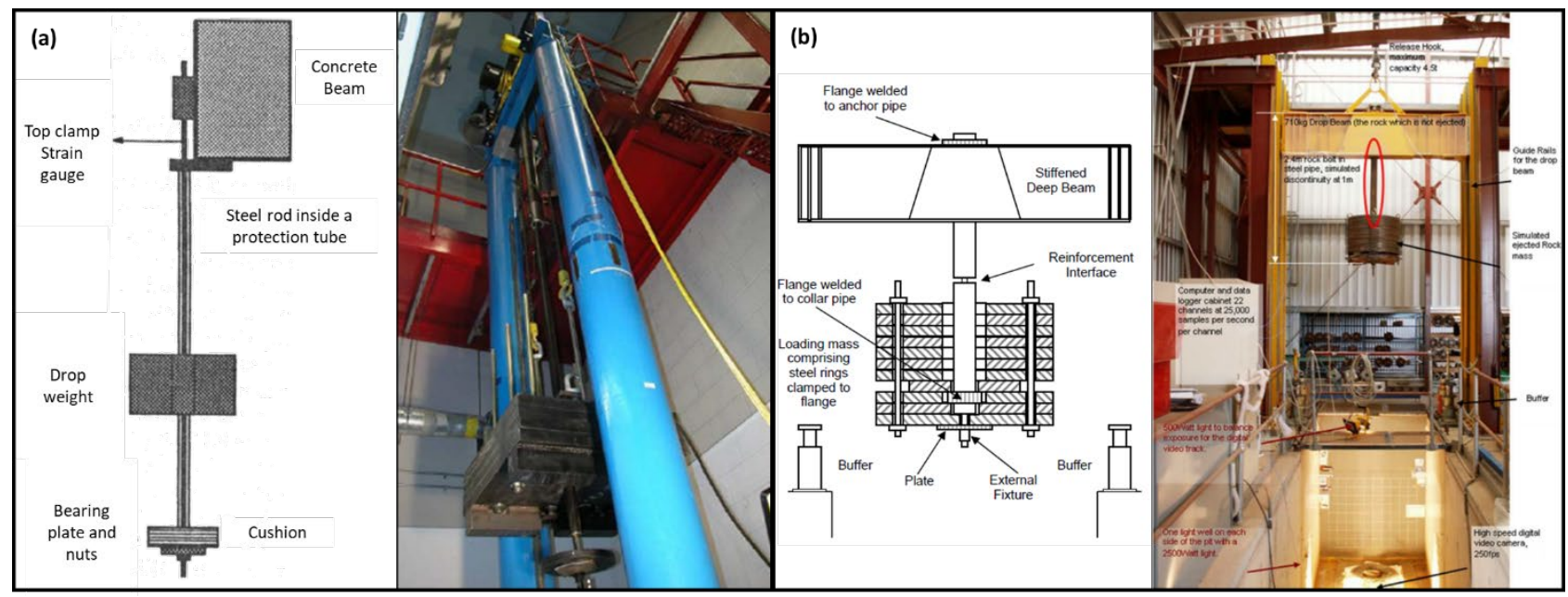

Figure 1 (a) Set-up of the dynamic testing facility at CanMet-MMSL (after Yi \& Kaiser 1992; 1994b);

(b) Set-up of the dynamic testing facility at WASM (after Player et al. 2004; 2008b)

With the development and construction of a laboratory-scale dynamic testing facility in Chile supported by the University of Chile and MIRARCO with a mechanism similar to the CanMet-MMSL motivated the development of the numerical model for reinforcement elements. In addition, several authors have questioned the effects of dynamic loads on rock reinforcements (Doucet \& Gradnik 2010; Wu et al. 2010; Li \& Doucet 2012; Doucet \& Voyzelle 2012) and those questions also inspired the numerical model summarised here. Most importantly, the response of threadbar using cement grout was selected in this first approach because of the urgent need to improve its performance under the dynamic conditions found in Chilean underground mining. Regrettably, due to restricted availability of threadbar results from CanMet-MMSL, only a limited comparison of results could be made with laboratory-scale dynamic test results from WASM which are available in the literature (Player \& Cordova 2009; Player et al. 2009). 


\subsection{Model and governing equations of motion}

Various efforts have been made to numerically represent the behaviour of dynamic tests for reinforcement elements used in underground excavations in recent years. Two approaches have been widely used within the computational mathematical area for the representation of this problem, the lumped-mass models and the dynamic deformation models in a continuum media. Lumped-mass models, which describe the reinforcement elements as discrete masses in series connected to each other by springs and dampers, have been used in models proposed since the beginning of dynamic studies programs for reinforcement elements. Tannant et al. (1995) were early proponents of such a model for the CanMet-MMSL test facility within the Rockburst Research Program of Canada. Thompson et al. (2004) used a similar model to describe the reinforcement behaviour in the WASM test facility. St-Pierre (2007) also use this approach in his master thesis, in which the cone bolt dynamic behaviour obtained at CanMet-MMSL facility was numerically modelled.

Dynamic deformation models use discrete elements to describe the behaviour of the reinforcement element as a continuous and deformable medium. In this approach, stress and deformation waves characterise the material behaviour in the elastic and plastic ranges through the propagation of the discretised elements in the medium. Ansell $(1999,2005)$ reviewed representative models of response under dynamic loads through this approach. Yi \& Kaiser (1994a) also used these models to describe the wave behaviour inside the reinforcement elements with this approach. It is important to note that dynamic deformation models and lumped-mass models have different objectives. The dynamic deformation models are more detailedoriented and focus on resolving problems related to specific components of a system, whereas lumped-mass models are more global and produce solutions involving the complete system.

Based on a more global objective to replicate the combined response of the rockbolt and the grout in the dynamic testing facilities, the approach illustrated in this section corresponds to the lumped-mass model. The model utilises the finite difference software FLAC3D (Itasca Consulting Group 2012), widely known in the geomechanical and geotechnical industry, for representing the dynamic testing facility and sample configuration as shown in Figure $2 \mathrm{a}$, in which the reinforcement element is represented by secondary elements (segments) joined together by nodes, as illustrated in Figure $2 \mathrm{~b}$.

(a)

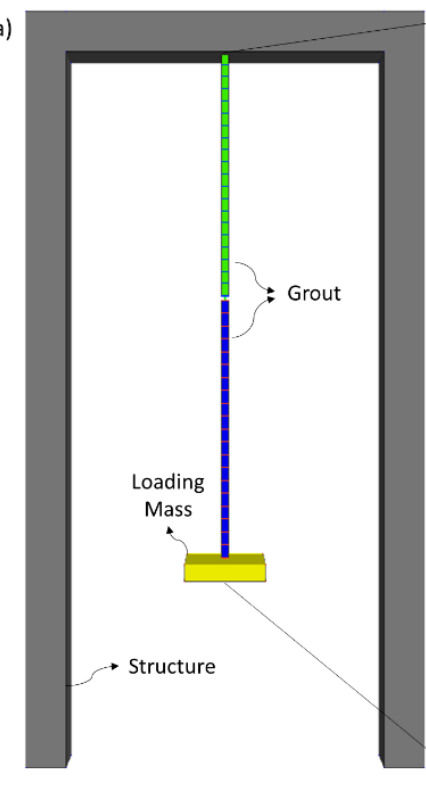

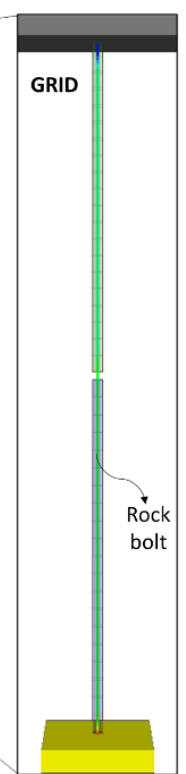

(b)

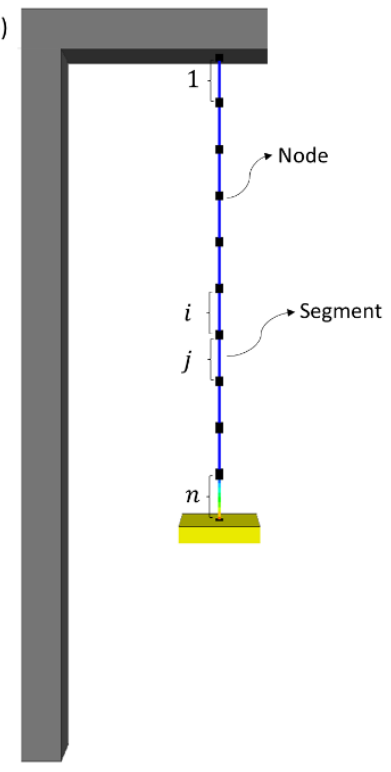

Figure 2 (a) Model scheme in FLAC3D Software; (b) Reinforcement element represented by segments joined by nodes

To characterise structures under certain applied dynamic force, diverse models use resolution schemes in which the whole system is simplified to be described through a damped oscillator. In this sense, the equations that describe the process are well known, as is their solution. However, the complexity of these systems lies 
in how the conditions of stiffness and damping are applied, incorporating difficulty in representing the real conditions of the problem. In order to solve the numerical model, the system is divided into two secondary problems as illustrated in Figure 3a. The first problem is described for the free fall of the mass used in the dynamic test until it impacts the plate (damping cushion in the current test) at a particular time of impact $\left(t_{i}\right)$. The second problem is in the interest of modelling, and it is after the moment of impact, when the mass begins to move along with the rockbolt, stretching it or sliding it until possible failure.

(a)

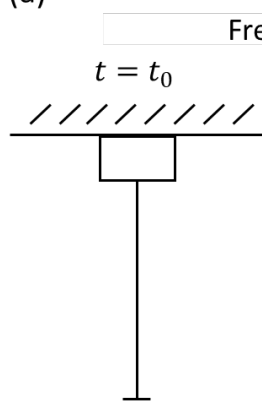

Free fall
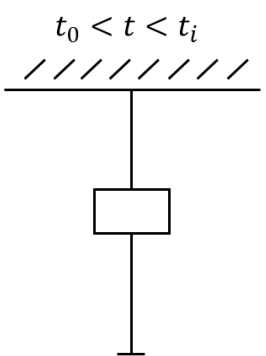

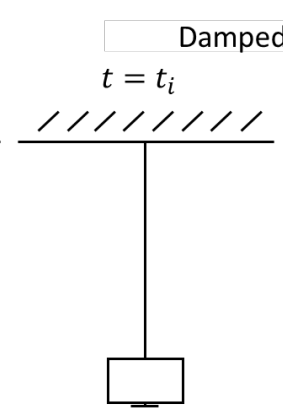

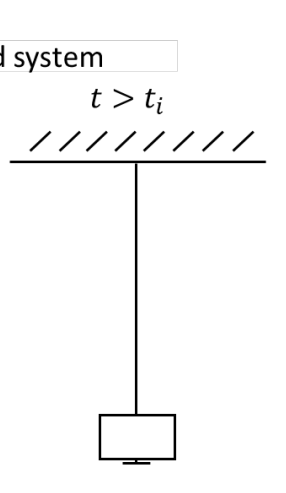

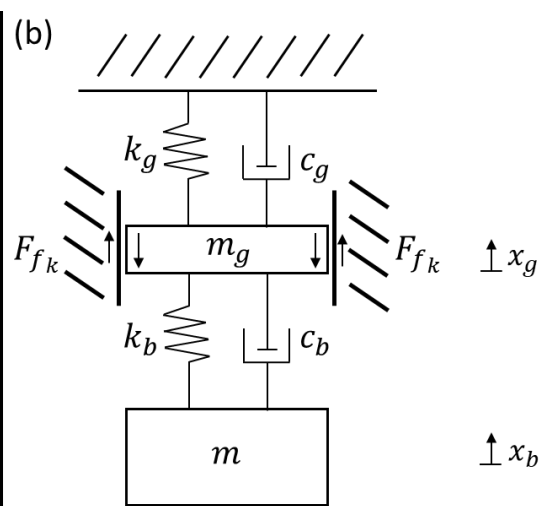

Figure 3 (a) Secondary problems of the model at different moments of time; (b) Free-body diagram of the model (after St-Pierre 2007)

After impacting the mass with the plate, the model is characterised as a simplified problem by the free-body diagram of the Figure $3 \mathrm{~b}$. Therefore, the system can be represented by two differential equations, in which the first describes the motion of the rockbolt and the second the motion of the grout, as presented in Equations 1 and 2 respectively. St-Pierre (2007) has shown a similar scheme in the development of his model for the cone bolt reinforcement element.

$$
\begin{gathered}
m \ddot{x}_{b}+c_{b}\left(\dot{x}_{b}-\dot{x}_{g}\right)+k_{b}\left(x_{b}-x_{g}\right)-F_{f_{k}}+m_{g}=0 \\
m_{g} \ddot{x}_{g}-c_{b}\left(\dot{x}_{b}-\dot{x}_{g}\right)-k_{b}\left(x_{b}-x_{g}\right)-c_{g} \dot{x}_{g}-k_{g} x_{g}+F_{f_{k}}=0
\end{gathered}
$$

where:

$$
\begin{aligned}
& m, m_{g}=\text { loading mass used in the dynamic test and grout mass, respectively. } \\
& g=\text { gravity constant. } \\
& k_{b}, k_{g}=\text { stiffness of rockbolt and grout, respectively. } \\
& c_{b}, c_{g}=\text { viscous damping of rockbolt and grout, respectively. } \\
& x_{b}, x_{g}=\text { displacement of rockbolt and grout, respectively. } \\
& \dot{x}_{b}, \dot{x}_{g}=\text { velocity of rockbolt and grout, respectively. } \\
& \ddot{x}_{b}, \ddot{x}_{g}=\text { acceleration of rockbolt and grout, respectively. } \\
& F_{f_{k}}=\text { friction force representing the contact between rockbolt and grout. }
\end{aligned}
$$

The motion equations are solved by an iterative numerical method - explicit in time combined with the unbalanced force criteria from FLAC3D. Notice that the mass of the rockbolt $\left(m_{b}\right)$ in Equation 1 and grout weight $\left(m_{g}\right)$ in Equation 2 are negligible in comparison with the loading mass of the dynamic test $(m)$, where the loading mass is about 200 times higher than the mass of the rockbolt, and therefore not taken into account in motion equations. The stiffness of the rockbolt and the grout shown in Equations 1 and 2 are approximated by their equivalent stiffness for systems connected in series (Rao \& Yap 2011). Furthermore, the viscous damping of the rockbolt and the grout shown in Equations 1 and 2 are proportional to their respective masses and stiffness, commonly known as classical damping of Rayleigh (1877). 
The properties of the rockbolt are well known and each manufacturer shows the properties of the material of its specific rock reinforcement element in their catalogues for static conditions. It is known that steel changes its yield limit and ultimate strength under dynamic loading conditions. Malvar \& Crawford (1998) shown that these magnitudes can be estimated by the elastic properties of steel scaling through a dynamic increase factor as illustrated in Equation 3.

$$
\begin{gathered}
D I F=\left(\frac{\dot{\varepsilon}}{10^{-4}}\right)^{\alpha} \\
\alpha_{f_{y}}=0.074-0.040 \frac{f_{y}}{414} \\
\alpha_{f_{u}}=0.019-0.009 \frac{f_{y}}{414}
\end{gathered}
$$

where:

$$
\begin{array}{ll}
\text { DIF } & =\text { dynamic increase factor } \\
\dot{\varepsilon} & =\text { strain rate } \\
f_{y} & =\text { yield limit of steel in static condition in } \mathrm{MPa} \\
\alpha_{f^{\prime}}, \alpha_{f_{u}} & =\text { coefficients for yield limit and ultimate strength of steel }
\end{array}
$$

In this case, the normal modes of vibration for rockbolts can be approximated from a steel bar embedded at one extreme as shown by Den Hartog (1985).

Due to the less homogeneous and less isotropic nature of the material, the cement grout is more difficult to model. Hyett et al. (1992) studied the behaviour of the cement grout through static tests for cable bolts, commonly known as pull-out tests. Through these tests, it was found that the properties depend mainly on the water-cement ratio used, the length of the embedding, and the radial confinement applied. However, in laboratory-scale testing, in which the borehole is simulated through a steel pipe, the external confinement effect is practically null. Due to the above, the radial stiffness exerted by the pipe that encapsulates the cement grout appears as a 'radial compression' and is implemented in the model through the formulation of Hyett et al. (1992).

On the other hand, to estimate the axial stiffness $\left(k_{g}\right)$ and the cohesive strength $\left(c_{g}\right)$ of the cement grout, the formulations of St John \& Van Dillen (1983), intrinsically present in FLAC3D, were used. In this case, since the interface of interest is between the grout and the rockbolt, the cohesive strength is evaluated in this interface. This is consistent with the in situ experience where the failure of most reinforcement elements occurs in the rockbolt/grout interface rather than the grout/rock interface. In addition, the normal modes of vibration for the grout are determined by the eigenvalues of the modal matrix, where the values of the normal modes are extrapolated to a damping system, as illustrated by Nilsson (2009).

Figure 4 shows three temporal stages of the dynamic test model with the split-tube sample configuration in FLAC3D, demonstrating how the numerical model represents the scheme shown in Figure 3a.

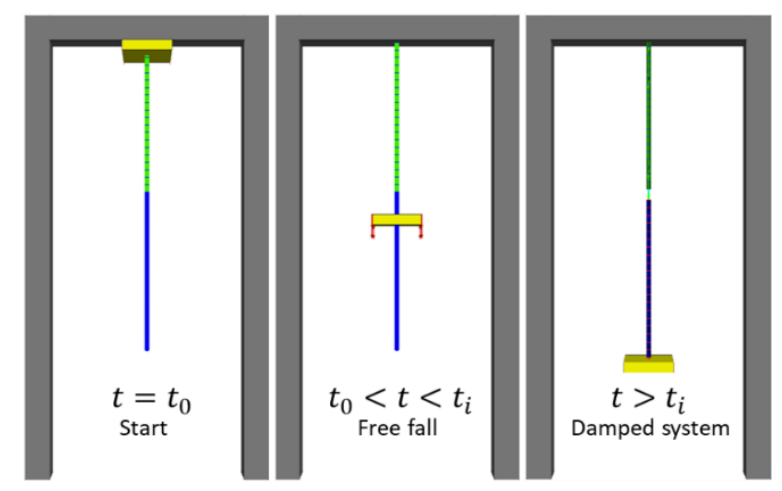

Figure 4 Solve scheme in FLAC3D Software; from left to right three temporal stages of the numerical model 


\subsection{Results and discussion}

The desired result in this case is to replicate the dynamic test response for reinforcement elements used in underground excavation, in particular for the threadbar. Figures $5 \mathrm{a}, 5 \mathrm{~b}$ and $5 \mathrm{c}$ show the comparison between the model (simulated curve) and laboratory-scale dynamic test results from the WASM Institute for threadbar with a debonded section (Player et al. 2009; Player \& Cordova 2009) for three different lengths of reinforcement. In these graphs, the similarity between numerical results and laboratory testing results can be appreciated. The parameters and coefficients used in the modelling are summarised in Table 1 . In addition, Figure $5 d$ illustrates a numerical example of the force, cement grout yielding state and bolt yielding state profiles of a sample of rockbolt of $3.2 \mathrm{~m}$ length at a final time stage of the model (when equilibrium has been reached).

The combined movement of the mass and the reinforcement element found by modelling during the simulation time generates a velocity profile, and corresponds directly to the results observed in laboratory testing. The velocity profile determines the oscillatory curve shape in the yield limit. This curve is consistent with how the dynamic increase factor is calculated, directly depending on the strain rate and thus the velocity profile (Equation 3). However, the basis of the oscillatory curve shape during the yielding condition may be explained by the hysteretic loading profile of the rockbolt when it reaches the dynamic plastic deformation zone. This zone is a result of the deformation of multiple segments, each of which deforms at different intervals producing overlapping responses. Therefore, a more accurate study to verify this explanation is necessary.

(a)

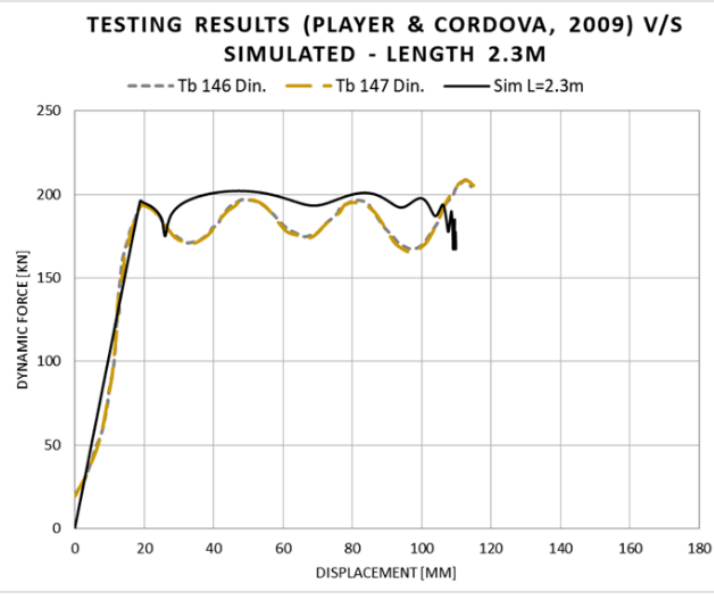

(b)

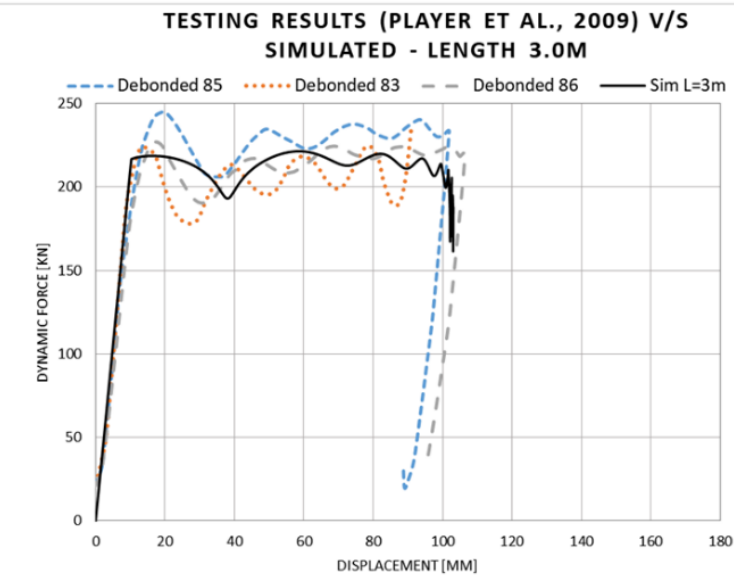

(c)

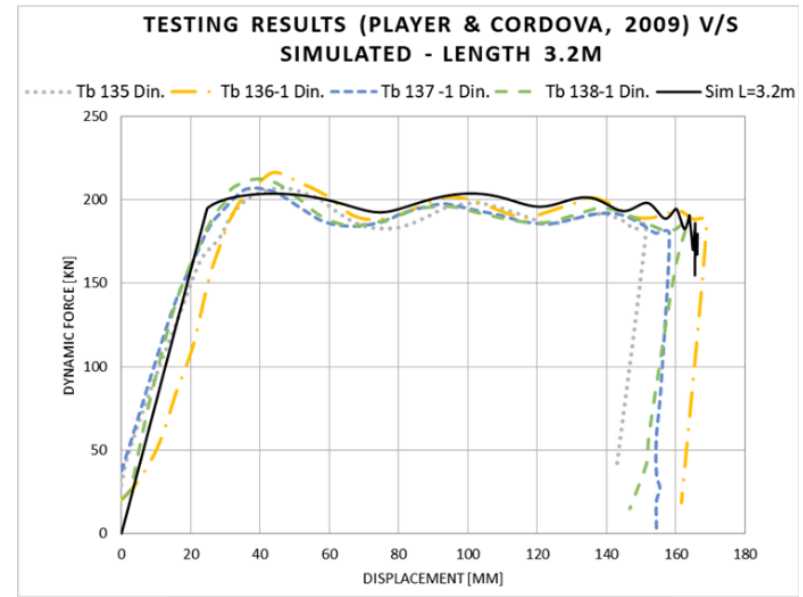

(d)

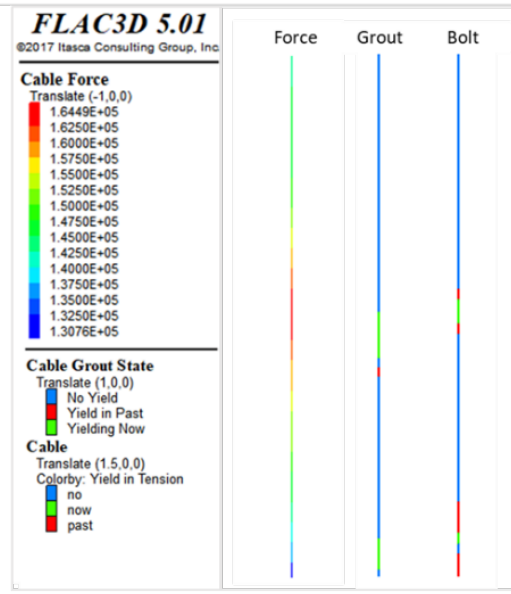

Figure 5 Model response comparison with test results: (a) $2.3 \mathrm{~m}$ rockbolt length; (b) $3.0 \mathrm{~m}$ rockbolt length; (c) 3.2 m rockbolt length (after Player et al. 2009; Player \& Cordova 2009); (d) Example of final force $(N)$, cement grout state and bolt state profiles for $3.2 \mathrm{~m}$ rockbolt length 
Table 1 Parameters of the modelling for three different dynamic tests (after Player et al. 2009; Player \& Cordova 2009)

\begin{tabular}{|c|c|c|c|c|c|c|c|c|c|c|}
\hline \multirow{3}{*}{$\begin{array}{l}\text { Length } \\
\text { (m) }\end{array}$} & \multirow{3}{*}{$\begin{array}{c}\text { Bar } \\
\text { diameter } \\
(\mathrm{mm})\end{array}$} & \multirow{3}{*}{$\begin{array}{c}\text { Loading } \\
\text { mass } \\
(\mathrm{kg})\end{array}$} & \multirow{3}{*}{$\begin{array}{c}\text { Impact } \\
\text { velocity } \\
(\mathrm{m} / \mathrm{s})\end{array}$} & \multirow{3}{*}{$\begin{array}{c}\text { Borehole } \\
\text { diameter } \\
(\mathrm{mm})\end{array}$} & \multirow{3}{*}{$\begin{array}{c}\text { Radial } \\
\text { stiffness } \\
(\mathrm{MPa} / \mathrm{mm})\end{array}$} & \multirow{3}{*}{$\begin{array}{c}\text { Energy } \\
\text { dissipated } \\
\text { (kJ) }\end{array}$} & \multicolumn{4}{|c|}{ Initial stiffness and damping } \\
\hline & & & & & & & Rock & kbolt & Cemen & tt grout \\
\hline & & & & & & & $\mathrm{k}(\mathrm{kN} / \mathrm{mm})$ & $\mathrm{c}(\mathrm{Ns} / \mathrm{mm})$ & $k(k N / m m)$ & $\mathrm{c}(\mathrm{Ns} / \mathrm{mr}$ \\
\hline 2.3 & 22 & 1,964 & 6.7 & 45 & 1,010 & 19.7 & 10.42 & 12 & 15.24 & 0.25 \\
\hline 3.0 & 22 & 1,964 & 7.6 & 45 & 1,010 & 20.9 & 21.06 & 16.43 & 19.38 & 2.09 \\
\hline 3.2 & 22 & 1,964 & 7.9 & 45 & 1,010 & 30.5 & 7.87 & 16.88 & 20.50 & 2.51 \\
\hline
\end{tabular}

For its part, the behaviour of the cement grout has a limited influence on the final strength of the reinforcement element (Figure 5). The cement grout mainly influences the initial stiffness and the velocity profile during the process. Furthermore, the cement grout slightly improves the damping of the system. However, if the cement grout is observed separately from the whole system, it reaches the yielding condition depending directly on the cohesive strength value without taking into account the grout friction angle (St John \& Van Dillen 1983). At this yielding point, the yielding condition is propagated partially or completely along the rockbolt due to the cohesive strength value used in the model. Nonetheless, the rockbolt reaches the yielding condition in some sections before the cement grout, even for low cohesive strength values. This generally agrees with observations made in laboratory-scale results of dynamic tests for threadbar (Player \& Cordova 2009; Player et al. 2009). It must be taken into account that the behaviour of the cement grout under dynamic conditions is an area that is just recently being researched, and for this reason the results found and parameters used by numerical modelling should be taken as an approximation of actual behaviour.

Finally, it is also important to remember that the model represents the CanMet-MMSL dynamic test facility, whereas the comparative results belong to the WASM dynamic test facility. As was noted previously, the results of tests from CanMet-MMSL for threadbar are restricted and not available for comparison. Then, the comparison of the model at this point could be made only with the limited number of tests available in the literature for threadbar that have been done at WASM. Furthermore, the choice of representing the CanMetMMSL dynamic test facility was made with the intention of applying the model to other reinforcement elements in the future, due to its similarity with the future laboratory-scale dynamic testing facility to be built in Chile. It should also be observed that the results shown by the CanMet-MMSL facility and the WASM facility for reinforcement elements other than the threadbar - the results of which are restricted as noted above - are generally the same in terms of the response and curve shape within a measurable range (Player et al. 2008b; Villaescusa 2012; Li \& Doucet 2012; Doucet \& Voyzelle 2012), even when both test facilities apply different concepts in their operation. In addition to the above, the model is adaptable and can be adjusted, if necessary, to extrapolate from and enhance the results of the future laboratory-scale dynamic testing facility to be built in Chile.

\section{Improvements in the numerical modelling of dynamic testing for reinforcement elements}

Continuing with the numerical modelling of the dynamic testing for reinforcement elements, the present section illustrates some improvements taken into account to achieve a better representation and response for threadbar. Therefore, a model of cement grout for numerical purposes and the progress to date towards an explicit numerical modelling of the dynamic testing for reinforcement elements are illustrated. 


\subsection{Grout modelling for numerical purposes}

\subsubsection{Grout strength degradation model}

Cement grout exhibit the phenomenon of strain softening under compressive loads. Thereby the non-linear strength degradation is highly stress dependant. As documented by triaxial test results from Hyett et al. (1992) and Xie et al. (2008), the confining pressure and the water:cement (w:c) ratio of the grout strongly influences the shape of the strength degradation as well as the value of residual strength. The strength degradation decreases with increasing confinement pressure. Finally, under high confinement pressure the grout becomes nearly ductile and no degradation occurs.

The cohesion-weakening-frictional-strengthening (CWFS) model proposed by Renani \& Martin (2018) allows definition of the variation of the degradation behaviour in relation to the confinement pressure. This proposal was enhanced to conserve the non-linear nature of damage and to avoid sharp changes in the rate of cohesion degradation and friction mobilisation, as Hajiabdolmajid et al. (2002) proposed. Equations 4 and 5 were then used to describe the cohesion degradation and friction mobilisation of brittle material as smooth functions of plastic strain.

$$
\begin{gathered}
c=c_{u}+\left(c_{i}+c_{u}\right)\left[2-\frac{2}{1+\exp \left(-3.66 \frac{\varepsilon^{p}}{\varepsilon_{c *}^{p}}\right)}\right] \\
\varphi=\varphi_{u}+\left(\varphi_{i}+\varphi_{u}\right)\left[\frac{2}{1+\exp \left(-3.66 \frac{\varepsilon^{p}}{\varepsilon_{\varphi *}^{p}}\right)}-1\right]
\end{gathered}
$$

where:

$$
\begin{aligned}
& c_{i}, c_{u}=\text { initial and degraded value of cohesion, respectively. } \\
& \varphi_{i}, \varphi_{u}=\text { initial and mobilised value of friction angle, respectively. } \\
& \varepsilon_{c *}^{p}, \varepsilon_{\varphi *}^{p}=\text { plastic strains at cohesion and friction angle within } 5 \% \text { of their ultimate values, respectively. }
\end{aligned}
$$

Based on the information from literature (Hyett et al. 1992; Xie et al. 2008), the estimated parameters of the CWFS model for 0.4 and $0.44 \mathrm{w}: \mathrm{c}$ ratio of the cement grout are given in Table 2, where $E$ and $v$ are the

\begin{tabular}{|c|c|c|c|c|c|c|c|c|c|c|c|c|}
\hline $\begin{array}{l}\text { W:C } \\
\text { ratio }\end{array}$ & $\begin{array}{c}\sigma_{i} \\
(\mathrm{MPa})\end{array}$ & $\begin{array}{c}\sigma_{u} \\
(\mathrm{MPa})\end{array}$ & $\begin{array}{c}E \\
\text { (GPa) }\end{array}$ & $v$ & $\varepsilon_{c *}^{p}$ & $\varepsilon_{\varphi *}^{p}$ & $\begin{array}{l}\varphi_{i} \\
\left(^{\circ}\right)\end{array}$ & $\begin{array}{l}\varphi_{u} \\
\left(^{\circ}\right)\end{array}$ & $\begin{array}{c}c_{i} \\
(\mathrm{MPa})\end{array}$ & $\begin{array}{c}c_{u} \\
(\mathrm{MPa})\end{array}$ & $\begin{array}{l}\text { Density* } \\
\left(\mathrm{g} / \mathrm{cm}^{3}\right)\end{array}$ & $\begin{array}{c}\text { Shear } \\
\text { strength* } \\
\text { (MPa) }\end{array}$ \\
\hline 0.44 & 36.12 & 30.19 & 10 & 0.25 & 0.017 & 0.005 & 21.4 & 28.5 & 12 & 7.6 & 1.98 & 3.9 \\
\hline 0.40 & 45.92 & 12.98 & 10 & 0.25 & 0.030 & 0.006 & 24.0 & 37.0 & 10 & 3.0 & 1.97 & 3.8 \\
\hline
\end{tabular}
modulus and Poisson's ratio of the cement grout, respectively. The variation of cohesion and friction and the corresponding stress-strain curves under triaxial compression tests are shown in Figure 6.

Table 2 Estimated parameters of the cohesion-weakening-frictional-strengthening (CWFS) model for 0.4 and 0.44 w:c ratio of the cement grout. * taken from Hyett et al. (1992) 
(a) 14
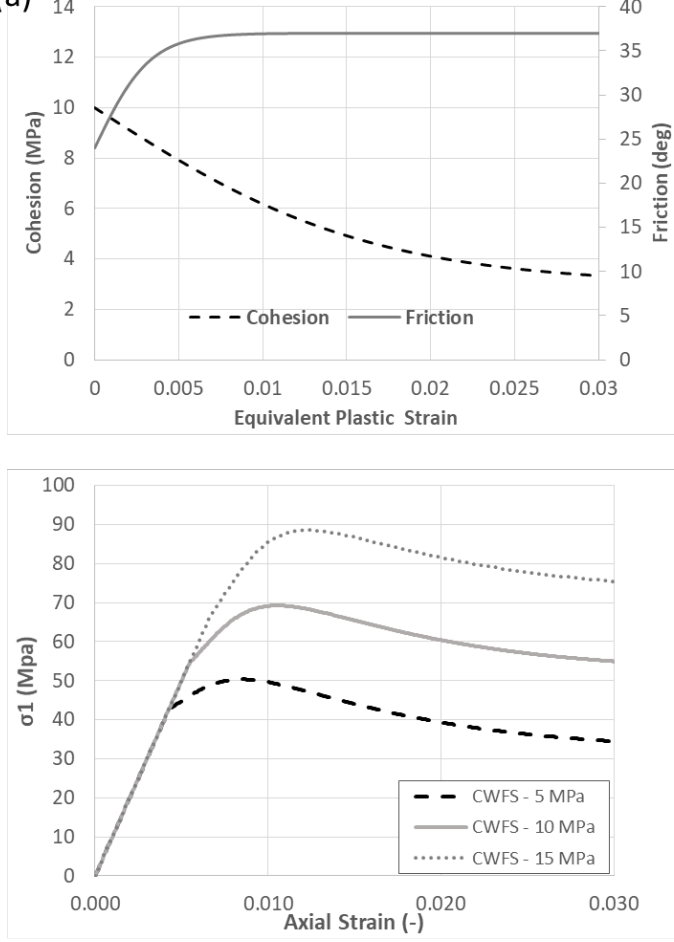

(b)
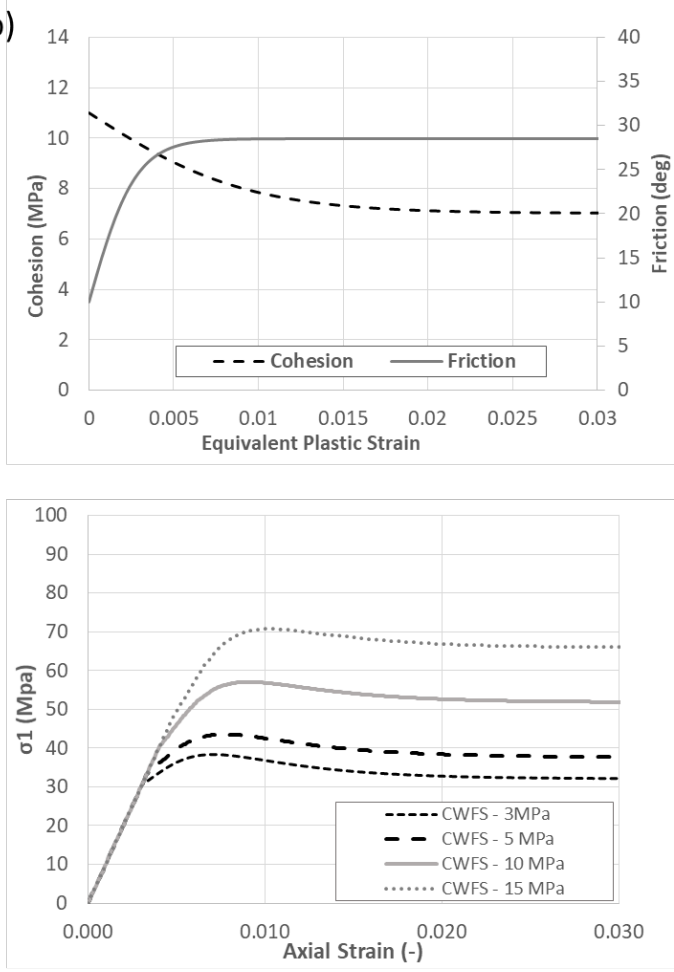

Figure 6 From top to bottom, cohesion loss and friction mobilisation and stress-strain curves under triaxial compression tests, respectively: (a) cohesion-weakening-frictional-strengthening (CWFS) model response for 0.4 w:c ratio of the cement grout; (b) CWFS model response for $0.44 \mathrm{w}: c$ ratio of the cement grout

The triaxial test data was analysed in order to deduce the main geotechnical features of the cement grout. Therefore, peak and residual Hoek-Brown failure criteria were also fitted to the peak and residual strength values obtained as a result of testing.

\subsubsection{Grout dilatancy model}

A reasonable parameter for evaluating plastic behaviour of cement grout is the dilation angle $\psi$. As radial and axial stress-strain curves are available only for $0.44 \mathrm{w}: \mathrm{c}$ ratio of the cement grout (Xie et al. 2008) for confinement pressures of $0,3,5$ and $20 \mathrm{MPa}$, a point cloud for these curves of dilation angle as a function of the plastic parameter $\gamma^{p}$ and confinement pressure applying the proposal of Arzúa \& Alejano (2013) was obtained, as shown in Figure 7. Alejano \& Alonso (2005) proposed a dilatancy angle model divided into two parts, one referring to the peak dilation angle $\psi_{\text {peak }}$ and the second part related to dilation angle decay with plasticity $K_{\psi}$ as is illustrated in Equations 6, 7 and 8.

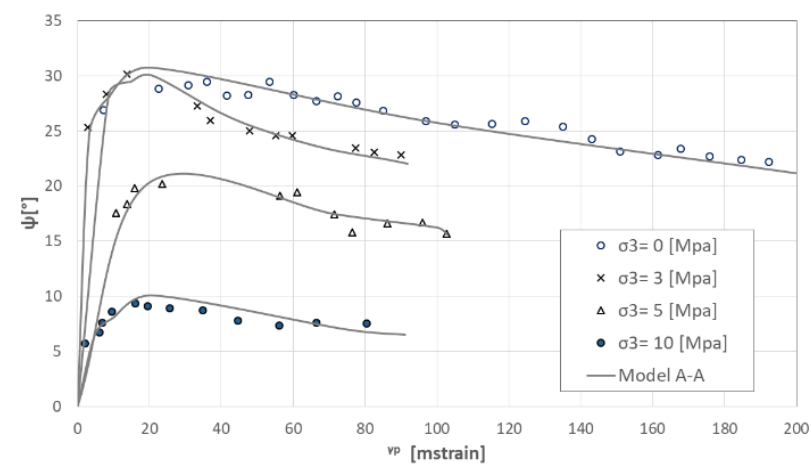

Figure 7 Dilatant behaviour for cement grout of 0.44 w:c ratio. Dilatancy from triaxial test compared with the model proposed by Alejano \& Alonso (2005) 


$$
\begin{gathered}
\psi_{\text {peak }}\left(\sigma_{3}\right)=\frac{\phi_{\text {peak }}}{1+\log _{10} \sigma_{c}} \log _{10}\left(\frac{\sigma_{c}}{\sigma_{3}+0.1}\right) \\
K_{\psi}=1+\left(K_{\psi_{\text {peak }}}\right) e^{-\gamma^{p} / \gamma^{p *}} \\
\gamma^{p *}=-\frac{\gamma^{p}}{\ln \left[\left(K_{\psi^{-1}}-1\right) /\left(K_{\left.\left.\psi_{\text {peak }}-1\right)\right]} \gamma^{p}=\left|\varepsilon_{1}^{p}-\varepsilon_{3}^{p}\right|\right.\right.}
\end{gathered}
$$

where:

$$
\begin{aligned}
& \psi_{\text {peak }}, \phi_{\text {peak }}=\text { peak dilation angle and peak friction angle, respectively. } \\
& K_{\psi}, K_{\psi_{\text {peak }}}=\text { dilation angle decay with plasticity and dilation angle decay peak, respectively. } \\
& \gamma^{p}, \gamma^{p *} \quad=\text { shear plastic strain and plasticity parameter constant, respectively. } \\
& \sigma_{c}, \sigma_{3}, \varepsilon_{1}^{p}, \varepsilon_{3}^{p}=\text { uniaxial compressive strength, confinement pressure, major and minor principal } \\
& \text { plastic strain, respectively. }
\end{aligned}
$$

\begin{tabular}{|c|c|c|c|c|c|}
\hline \multicolumn{4}{|c|}{$K_{\psi}$} & \multirow{2}{*}{$\begin{array}{c}\gamma^{p} \\
\text { (mstrain) }\end{array}$} & \multirow{2}{*}{$\begin{array}{c}\gamma^{p *} \\
\text { (mstrain) }\end{array}$} \\
\hline$\sigma_{3}=0(\mathrm{MPa})$ & $\sigma_{3}=3(\mathrm{MPa})$ & $\sigma_{3}=5(\mathrm{MPa})$ & $\sigma_{3}=15(\mathrm{MPa})$ & & \\
\hline 20 & 21 & 28 & 30 & 25 & 20 \\
\hline
\end{tabular}

Using the above mentioned approach, the dilatancy angle for cement grout with 0.4 w:c ratio was estimated for confinement pressures of 0, 5, 15 and $20 \mathrm{Mpa}$. Hence, three coefficients are necessary to fit each one of the curves shown in Figure 7. These coefficients are presented in Table 3.

Table 3 Fit coefficients for dilation angle-plastic parameter curves for cement grout of 0.4 w:c ratio

Dilatancy from laboratory test results were compared with the models proposed at different confinement pressures and plotted as shown in Figure 7. The model fits the laboratory data in terms of peak friction angle and the process of dilation decay.

Therefore, Figure 7 reveals the expected behaviour, where it can be observed the dilation angle dependency as pointed out by Alejano \& Alonso (2005). Then, the dilation angle depends first on confinement pressure (i.e. as confinement pressure increase, the dilation angle diminishes), and second on plastic shear strain (i.e. as plastic shear strain develops, the dilation angle decay).

\subsubsection{Numerical modelling for verification of mechanical properties of the grout}

A series of 3D numerical simulations of triaxial compression tests of a Mohr-Coulomb strain softening material were conducted in FLAC3D. The model was constructed to represent a cylindrical cement grout sample of $100 \mathrm{~mm}$ height and $50 \mathrm{~mm}$ diameter. A constant velocity of $5 \times 10^{-8} \mathrm{~m} / \mathrm{step}$ was applied at the top and bottom of the sample, respectively. During the simulation of the triaxial loading process, the elements deform and reveal degradation and dilation. Considering the strength heterogeneity, the elements undergoing degradation and dilation will coalesce and then lead to the formation of macroscopic fractures. The simulated stress - axial strain curves under confinement pressures of 3, 5, 10 and $15 \mathrm{MPa}$ for 0.4 and $0.44 \mathrm{w}: \mathrm{c}$ ratio of the cement grout with analogous results from actual tests are shown in Figure 8. 

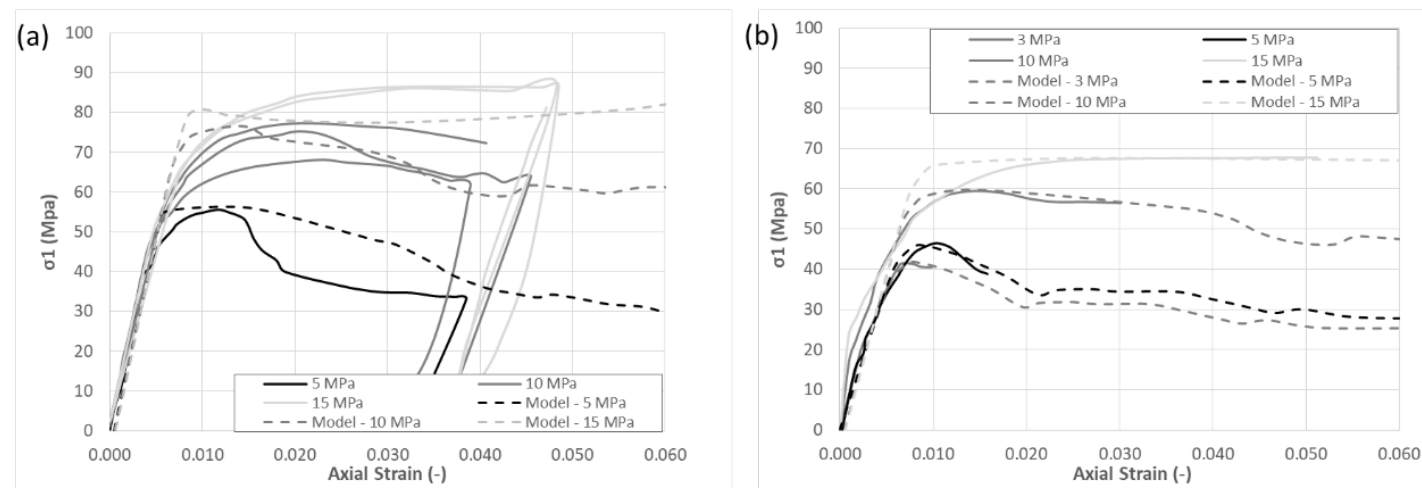

Figure 8 Comparison of complete set of stress-strain curves for different confinement pressures with laboratory results: (a) $0.4 \mathrm{w}: \mathrm{c}$ ratio of the cement grout; (b) $0.44 \mathrm{w:c}$ ratio of the cement grout

Material softening, upon shear or tensile failure, is defined by tables where friction angle, cohesion and dilatancy angle are related to plastic shear strain as was shown previously. The total stress-total axial strain results presented in Figure 8 together with analogous results from actual tests reveal good agreement in terms of uniaxial compressive strength, residual strength, yielding point and softening behaviour for the cement grout. In this context, despite the models for strength degradation and dilatancy were proposed for rock material, it is observed that these can be adjusted for more homogeneous materials such as cement grout.

Constitutive model and sets of mechanical parameters including friction angle, cohesion and dilatancy angle as function of plastic strain for cement grout were integrated in an update of the numerical model of dynamic testing for reinforcement elements summarised previously in section 2 (Marambio et al. 2018).

\subsection{Towards an explicit numerical modelling of dynamic testing}

With the aim of achieving a model that represents more precisely the behaviour of the threadbar under dynamic loading, an explicit numerical modelling of the dynamic testing is in development and still in the calibration process. Main components were replaced by explicit elements that represent the rockbolt, the grout and the split encapsulating tube instead of the cable element that was used in the previous model (Marambio et al. 2018). In addition, the mechanical behaviour of grout stablished in section 3.1 and an interface that allows to represent the possible slippage between the rockbolt and the grout were integrated to the principal FLAC3D model. The model defines the movement and the impact of the loading mass as in the previous model, the difference in the behaviour of the rockbolt lies mainly in the fallowing aspects:

- The equations of motion are invoked to derive new nodal velocities, displacements and forces in each zone representing the rockbolt. In this sense, new strain rates are derived from nodal velocities to apply the dynamic increase factor proposed by Malvar \& Crawford (1998) in a constitutive model elastic-perfectly plastic. This is repeated at every time step of calculation until the system reaches equilibrium.

- The confinement imposed by the encapsulating tube is represented by a structural element type DKT-CSTH shell (Itasca Consulting Group 2012) being its constitutive behaviour elastic-perfectly plastic. 
The new geometry of the problem tries to better represent the real problem and is expected to be adaptable to other reinforcement elements in future updates. Figure 9 illustrates an example of the new numerical modelling implemented in FLAC3D.

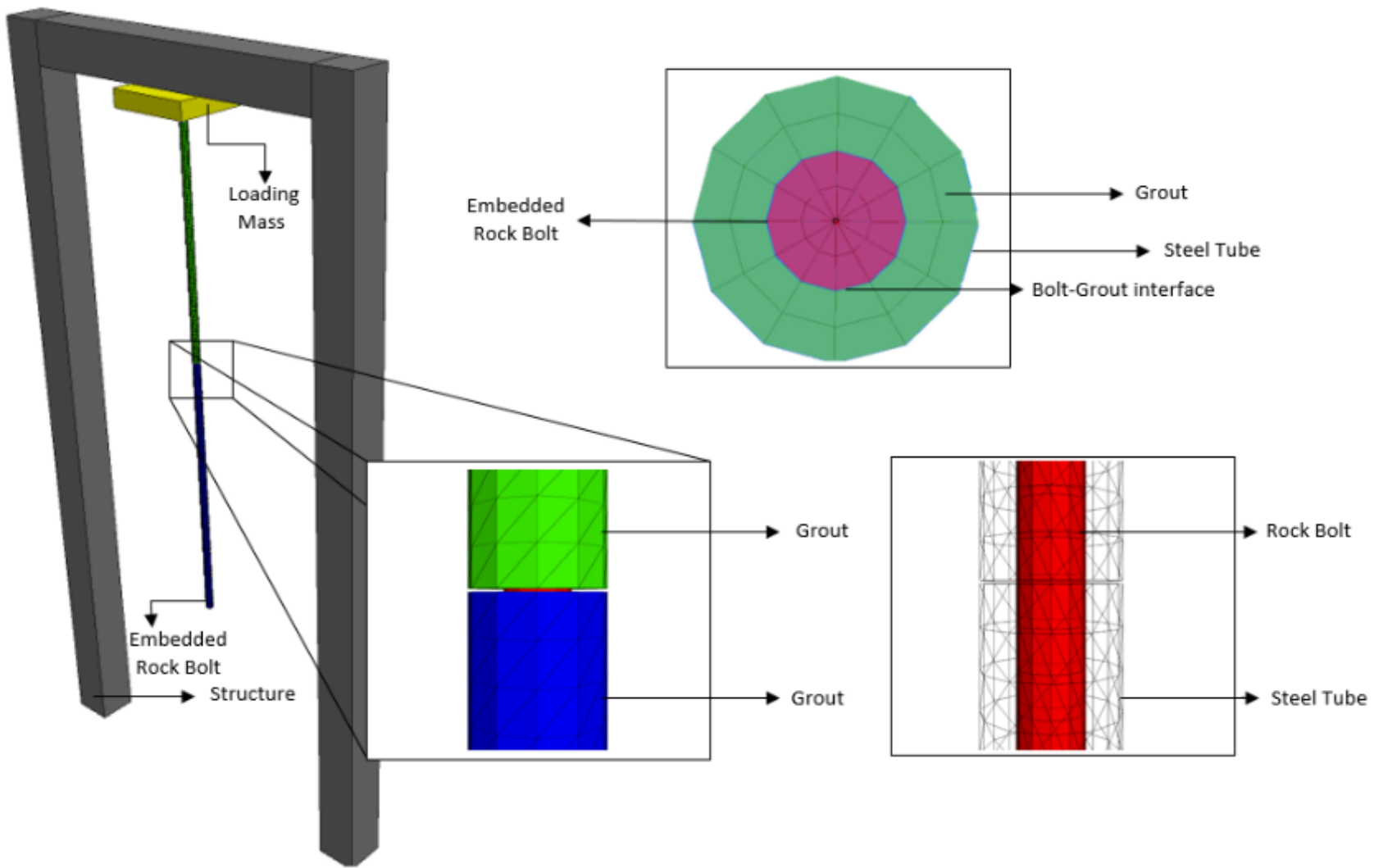

Figure 9 Example of the new geometry for the numerical problem implemented in FLAC3D

\section{Development of numerical modelling of dynamic test for retaining elements}

The research of underground excavations under dynamic loads involves several studies in which each element of the complete support system is tested separately. Retaining elements are the complement of reinforcement elements and its study under dynamic loads is necessary to understand its behaviour, performance and strength. Therefore, since the early 1980s a number of authors have performed laboratory-scale static testing programs for retaining elements, using the program implemented by Player et al. (2008a) at WASM (Figure 10a) which is probably the most recognised today. Due to high costs in time and validation of these testing programs, numerical modelling of laboratory-scale testing facilities appears as an alternative to analyse and quantify the performance of retaining elements in order to extrapolate and enhance previous results. However, the numerical modelling of these testing facilities is an area still in development at the present time. In this context, the work performed by Karampinos et al. (2018), in which numerical modelling was used to represent the behaviour of a steel wire mesh under static load at the WASM testing facility, is perhaps the most recent approach that uses this methodology to analyse the response of retaining elements in a testing facility. 
(a)

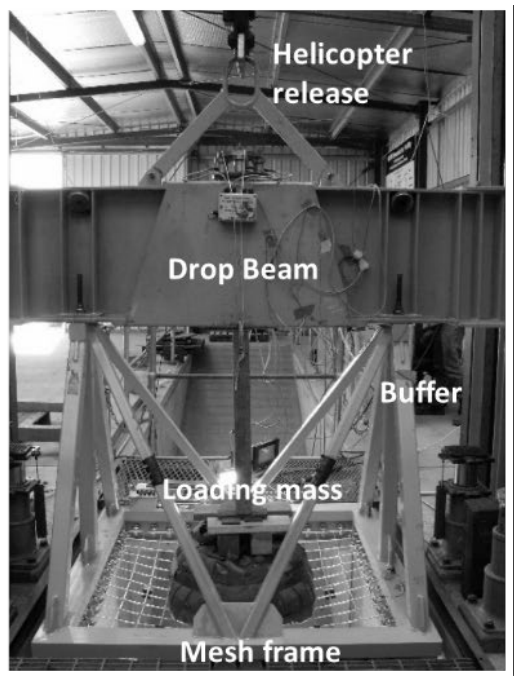

(b)

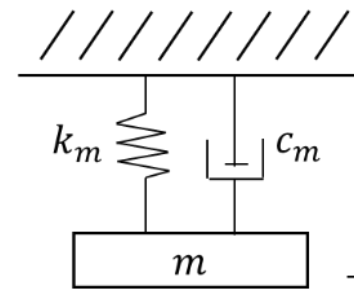

(c)

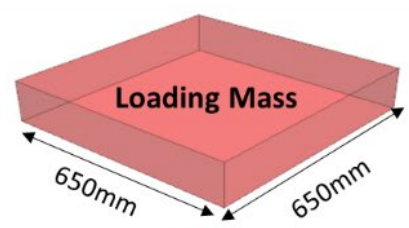

$\perp x_{m}$

Figure 10 (a) Dynamic testing facility of retaining elements at WASM; (b) Free-body diagram of the problem; (c) Dynamic testing model of retaining elements in FLAC3D

Therefore, based on the work done mainly by Karampinos et al. (2018) and Morton et al. (2007), the present section illustrates the progress to date for the numerical modelling of the dynamic response of steel wire mesh under laboratory-scale conditions, aiming to simulate the WASM dynamic testing facility. For the above, a simple damping oscillatory system, as illustrated in Figure 10b, is used to represent the dynamic behaviour of the steel wire mesh under a dynamic load applied by a mass that freely falls and impacts the steel wire mesh. In this approach, due to its common implementation in Chilean mining, and globally, the steel welded wire mesh is used as a sample to analyse the behaviour of a surface retaining element under the laboratory-scale dynamic test through numerical modelling in FLAC3D.

The model is characterised then by the motion of a simple oscillatory system described by Equation 9 . The constitutive model for the steel is assumed as elastic-perfectly plastic, including the dynamic increase factor for the yielding limit as was illustrated by Malvar \& Crawford (1998) through a FISH Code (programming language of FLAC3D). The maximum plastic moment capacity and maximum deflection of each steel section of $100 \mathrm{~mm}$ that conforms the square patron of the welded wire mesh can be easily calculated by Equation 10 as was shown previously by Karampinos et al. (2018).

$$
\begin{gathered}
m \ddot{x}_{m}+c_{m} \dot{x}_{m}+k_{m} x_{m}-m g=0 \\
M_{p}=\frac{\sigma_{y} I}{c} S=\frac{M_{p} L^{2}}{12 E I}
\end{gathered}
$$

where:

$$
\begin{aligned}
& m, k_{m}, c_{m}, x_{m}, \dot{x}_{m}, \ddot{x}_{m}=\text { loading mass of the test; stiffness, viscous damping, displacement, } \\
& M_{p}, S, \sigma_{y}, I, c, L, E \quad=\text { moment capacity, maximum deflection, yield stress, moment of inertia, }
\end{aligned}
$$

In this approach the classical viscous damping of Rayleigh (1877) was used to describe the behaviour of the welded wire mesh under the dynamic load applied by the testing facility. The model constructed in FLAC3D is illustrated in Figure 10c where the dimension of the elements preserve the dimensions described for the dynamic test (Karampinos et al. 2018; Player et al. 2008a). An iterative explicit in time sequence was used to solve the problem and the result was compared with a previous result from literature (Player et al. 2008a). Figures 11a, 11b and 11c show an example of evolution of the force response in time in the numerical modelling. Whereas Figure 11d illustrates the comparison between the dynamic response of the welded wire mesh at the WASM facility and the response of the numerical model. 
(a)

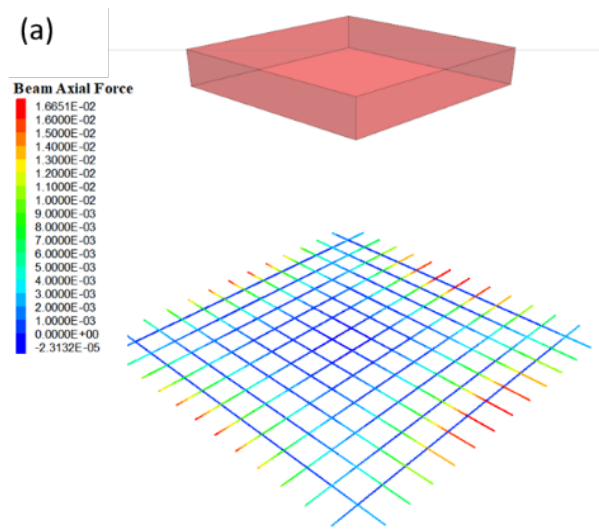

(b)
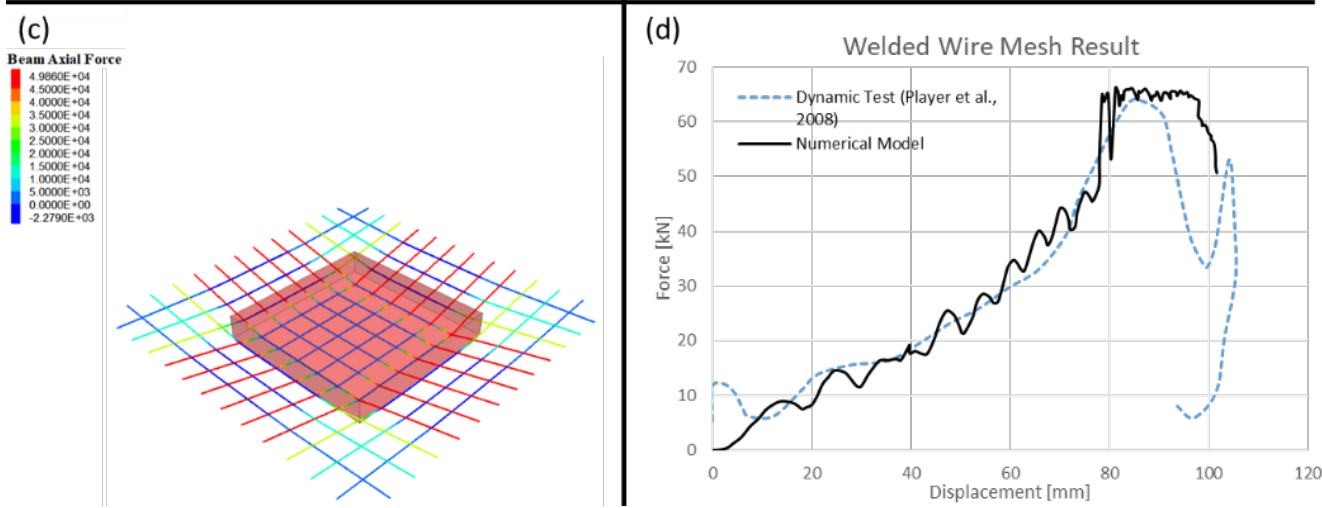

Figure 11 (a) Initial state of the numerical modelling; (b) Impact of the loading mass in the numerical modelling; (c) State after impact in the numerical modelling; (d) Comparison of response with literature (Player et al. 2008a)

Based on the results illustrated previously, it can be noted that through the numerical modelling the response of the steel welded wire mesh depends mainly on the strain rate generated by the impact and contact between the loading mass and its surface. In this sense, the response is similar with the previous result of the threadbar, where the relations shown by Malvar \& Crawford (1998) are achieved.

At this point of work, it should be noticed that the dynamic testing in the numerical modelling uses the energy transfer concept rather than the momentum transfer concept applied by the WASM dynamic testing facility, this was a change that was made to simplify the problem in this first approach. On the other hand, the three welded wire mesh failure mechanisms as were illustrated by Player et al. (2008a) up to this moment have not been taken into account in the numerical modelling, however, how to identify these failures in a appropriated way through the modelling is in development. Despite the limitations mentioned, the result achieved to this point is reasonable and represents a tool that can be improved upon to represent the complete behaviour of this retaining element and others.

\section{Conclusion}

For both the reinforcement element and the retaining element, the direct relationship among the propagation velocity through these elements, the dynamic increase of their yielding point, and their ultimate strength is appreciable through the numerical modelling. Consistent with the observations of Malvar \& Crawford (1998), these variables, appreciable during the simulation time, have a distinct influence on the limit and the oscillatory profile of the yielding condition in these elements.

For its part, based on the first modelling of the reinforcement elements, cement grout plays a secondary role in the overall strength of the system, mainly influencing the system's initial stiffness and initial damping. Therefore, in order to improve its behaviour, a calibrated CWFS model was implemented to the cement grout considering the friction angle, cohesion and dilatancy angle. This model was proposed previously for rock material. 
Based on the cement grout model, it is expected to obtain a more realistic representation of the dynamic testing for reinforcement elements, especially for threadbar in a new explicit numerical modelling that improves the behaviour of the cable elements implicitly present in FLAC3D. Nevertheless, numerical modelling results to this date represent a valuable tool to visually support, enhance and illustrate the dynamic processes of reinforcement elements and retaining elements under laboratory-scale dynamic testing.

\section{Acknowledgement}

The authors gratefully acknowledge the financial support from basal CONICYT project AFB180004 of the Advanced Mining Technology Center (AMTC) and the project 16CONTEC-65103 'Mejoramiento de las características dinámicas del perno helicoidal para la minimización de interferencias operacionales y riesgo asociado a la ocurrencia de sismicidad inducida por la minería subterránea' financed in conjunction with CORFO Innova and Compañía de Aceros del Pacífico. In addition, the second author thanks CODELCO and CODELCOTech for the distinction through their 'Piensa Minería' grant. Finally, the 'Laboratorio de Geomecánica y Diseño Minero' is personally acknowledged for its infinite support during the development of this document.

\section{References}

Alejano, LR \& Alonso, E 2005, 'Considerations of the dilatancy angle in rocks and rock masses', International Journal of Rock Mechanics and Mining Sciences, vol. 42, pp. 481-507.

Ansell, A 1999, Dynamically Loaded Rock Reinforcement, Institutionen för Byggkonstruktion.

Ansell, A 2005, 'Laboratory testing of a new type of energy absorbing rock bolt', Tunnelling and Underground Space Technology, Elsevier, vol. 20, no. 4, pp. 291-300.

Arzúa, J \& Alejano, LR 2013, 'Dilation in granite during servo-controlled triaxial strength tests', International Journal of Rock Mechanics and Mining Sciences, vol. 61, pp. 43-56.

Brändle, R, Rorem, E, Luis, R \& Fischer, G 2017, 'Full-scale dynamic tests of a ground support system using high-tensile strength chain-link mesh in El Teniente mine, Chile', Proceedings of the First International Conference on Underground Mining Technology, Australian Centre for Geomechanics, Perth, pp. 25-43.

Cai, M \& Kaiser, PK 2018, Rockburst Support Reference Book. Volume I: Rockburst phenomenon and support characteristics, MIRARCO - Mining Innovation, Laurentian University, Sudbury.

Crompton, B, Berghorst, A \& Knox, G 2018, 'A new dynamic test facility for support tendons', Australian Centre for Geomechanics Newsletter, vol. 47, August, viewed 19 January 2019, https://www.ncm.co.za/downloads/papers_presentations/ ACG_Newsletter_August2018.pdf

Den Hartog, JP 1985, Mechanical Vibrations, Dover Publications, New York.

Dolinar, D 2006, 'Load capacity and stiffness characteristics of screen materials used for surface control in underground coal mines', in SS Peng (ed), Proceedings of the 25th International Conference on Ground Control in Mining, National Institute for Occupational Safety and Health (US), United States Mine Safety and Health Administration, West Virginia Coal Association, West Virginia University, pp. 152-158.

Doucet, C \& Gradnik, R 2010, 'Recent developments with the Roofex ${ }^{\mathrm{TM}}$ bolt', in M Van Sint Jan \& Y Potvin (eds), Proceedings of the Fifth International Seminar on Deep and High Stress Mining, Australian Centre for Geomechanics, Perth, pp. 353-366.

Doucet, C \& Voyzelle, B 2012, Technical information data sheets, Canmet-Mining, Ottawa, Canada.

Hajiabdolmajid, V, Kaiser, PK \& Martin, CD 2002, 'Modelling brittle failure of rock', International Journal of Rock Mechanics and Mining Sciences, vol. 39, pp. 731-741.

Hyett, AJ, Bawden, WF \& Reichert, RD 1992, 'The effect of rock mass confinement on the bond strength of fully grouted cable bolts', International Journal of Rock Mechanics and Mining Sciences \& Geomechanics Abstracts, Elsevier, vol. 29, iss. 5, pp. 503-524.

Itasca Consulting Group 2012, User's Manual of FLAC3D (Structural Elements).

Kaiser, PK, McCreath, DR \& Tannant, DD 1996, Canadian Rockburst Support Handbook, Geomechanics Research Centre, Laurentian University, Sudbury, $314 \mathrm{p}$.

Karampinos, E, Baek, B \& Hadjigeorgiou, J 2018, 'Discrete element modelling of a laboratory static test on welded wire mesh', in Y Potvin \& J Jakubec (eds), Proceedings of the Fourth International Symposium on Block and Sublevel Caving, Australian Centre for Geomechanics, Perth, pp. 735-746.

Li, CC \& Doucet, C 2012, 'Performance of D-bolts under dynamic loading', Rock Mechanics and Rock Engineering, vol. 45, no. 2, pp. 193-204.

Malvar, LJ \& Crawford, JE 1998, 'Dynamic increase factors for steel reinforcing bars [C]', 28th DDESB Seminar, Orlando, USA.

Marambio, E, Vallejos, JA, Burgos, L, Gonzalez, C, Castro, L, Saure, JP \& Urzua, J 2018, 'Numerical modelling of dynamic testing for rock reinforcement used in underground excavations', in Y Potvin \& J Jakubec (eds), Proceedings of the Fourth International Symposium on Block and Sublevel Caving, Australian Centre for Geomechanics, Perth, pp. 767-780.

Morton, EC, Thompson, AG, Villaescusa, E \& Roth, A 2007, 'Testing and analysis of steel wire mesh for mining applications of rock surface support', Proceedings of the 11th ISRM Congress, International Society for Rock Mechanics and Rock Engineering. 
Nilsson, C 2009, Modelling of Dynamically Loaded Shotcrete, Royal Institute of Technology.

Ortlepp, WD 1983, 'Considerations in the design of support for deep hard-rock tunnels', in Proceedings of the Fifth ISRM Congress, International Society for Rock Mechanics and Rock Engineering.

Pakalnis, V \& Ames, D 1983, 'Load tests on mine screening', Underground Support Systems, special volume 35, Canadian Institute of Mining, Metallurgy and Petroleum, Montreal, p. 23.

Player, J \& Cordova, M 2009, Dynamic Threadbar Test at WASM, Internal report for CODELCO - El Teniente Mine.

Player, JR, Morton, EC, Thompson, AG \& Villaescusa, E 2008a, 'Static and dynamic testing of steel wire mesh for mining applications of rock surface support', Proceedings of the Sixth International Symposium on Ground Support in Mining and Civil Engineering Construction, South African National Institute of Rock Engineering (SANIRE) \& The Southern African Institute of Mining and Metallurgy (SAIMM), pp. 693-706.

Player, JR, Thompson, AG \& Villaescusa, E 2008b, 'Dynamic testing of reinforcement systems', in TR Stacey \& D Malan (eds), Proceedings of the 6th International Symposium on Ground Support in Mining and Civil Engineering Construction, The Southern African Institute of Mining and Metallurgy, Johannesburg, pp. 581-595.

Player, JR, Villaescusa, E \& Thompson, AG 2004, 'Dynamic testing of rock reinforcement using the momentum transfer concept', in E Villaescusa \& Y Potvin (eds), Proceeding in Fifth International Symposium on Ground Support, A.A. Balkema, Rotterdam, pp. 327-339.

Player, JR, Villaescusa, E \& Thompson, AG 2009, 'Dynamic testing of threadbar used for rock reinforcement', in M Diederichs \& G Grasselli (eds), Proceedings of RockEng09: Rock Engineering in Difficult Conditions, paper 4030, Canadian Institute of Mining, Metallurgy and Petroleum, Westmount.

Rao, SS \& Yap, FF 2011, Mechanical Vibrations, Prentice Hall, Upper Saddle River.

Rayleigh, L 1877, Theory of Sound (two volumes), Re-issue, Dover Publications, New York.

Renani, HR \& Martin, CD 2018, 'Modeling the progressive failure of hard rock pillars', Tunnelling and Underground Space Technology, vol. 74, pp. 71-81.

Roth, A, Windsor, CR, Coxon, J \& de Vries, R 2004, 'Performance assessment of high tensile wire mesh ground support under seismic conditions', in E Villaescusa \& Y Potvin (eds), Proceedings of the Fifth International Symposium on Ground Support in Mining and Underground Construction, CRC Press, London, pp. 589-594.

St John, CM \& Van Dillen, DE 1983, 'Rockbolts: a new numerical representation and its application in tunnel design', The 24th US Symposium on Rock Mechanics (USRMS), American Rock Mechanics Association.

St-Pierre, L 2007, Development and Validation of a Dynamic Model for a Cone Bolt Anchoring System, masters thesis, McGill University, Montreal.

Tannant, D, Kaiser, PK \& Maloney, S 1997, 'Load-displacement properties of welded-wire, chain-link and expanded metal mesh', in E Broch, A Myrvang \& G Stjern (eds), Proceedings of the International Symposium on Rock Support: Applied Solutions for Underground Structures, Lillehammer, pp. 651-659.

Tannant, DD, Brummer, RK \& Yi, X 1995, 'Rockbolt behaviour under dynamic loading: field tests and modelling', International Journal of Rock Mechanics and Mining Sciences \& Geomechanics Abstracts, Elsevier, pp. 537-550.

Thoeni, K, Lambert, C, Giacomini, A \& Sloan, SW 2013, 'Discrete modelling of hexagonal wire meshes with a stochastically distorted contact model', Computers and Geotechnics, vol. 49, pp. 158-169.

Thompson, AG, Player, JR \& Villaescusa, E 2004, 'Simulation and analysis of dynamically loaded reinforcement systems', in E Villaescusa \& Y Potvin (eds), Proceedings of the Fifth International Symposium on Ground Support in Mining and Underground Construction, CRC Press, London, pp. 341-355.

Thompson, AG, Windsor, CR \& Cadby, GW 1999, 'Performance assessment of mesh for ground control applications', Rock Support and Reinforcement Practice in Mining, Routledge, pp. 119-130.

Van Sint Jan, M \& Cavieres, P 2004, 'Large scale static laboratory test of different support systems', in E Villaescusa \& Y Potvin (eds), Proceedings of the Fifth International Symposium on Ground Support in Mining and Underground Construction, CRC Press, London, pp. 571-577.

Villaescusa, E 2012, Static and dynamic laboratory testing of rock reinforcement - El Teniente Mine, Western Australian School of Mines, Curtin University of Technology, Kalgoorlie.

Wu, R, Oldsen, J \& Lamothe, M 2010, 'The Yield-Lok bolt for bursting and squeezing ground support', in M Van Sint Jan \& Y Potvin (eds), Proceedings of the Fifth International Seminar on Deep and High Stress Mining, Australian Centre for Geomechanics, Perth, pp. 301-308.

Xie, SY, Shao, JF \& Burlion, N 2008, 'Experimental study of mechanical behaviour of cement paste under compressive stress and chemical degradation', Cement and Concrete Research, vol. 38, pp. 1416-1423.

Yi, X \& Kaiser, PK 1992, 'Stress in dynamically loaded rockbolts with rubber and wood cushions', in PK Kaiser \& DR McCreath (eds), Proceedings of the International Symposium on Rock Support: Rock Support in Mining and Underground Construction, A.A. Balkema, Rotterdam, pp. 683-691.

Yi, X \& Kaiser, PK 1994a, 'Elastic stress waves in rockbolts subject to impact loading', International Journal for Numerical and Analytical Methods in Geomechanics, vol. 18, no. 2, pp. 121-131.

Yi, X \& Kaiser, PK 1994b, 'Impact testing for rockbolt design in rockburst conditions', International Journal of Rock Mechanics and Mining Sciences \& Geomechanics Abstracts, vol. 31, no. 6, pp. 671-685. 
Progress in the numerical modelling of dynamic testing for reinforcement and retaining elements used in underground excavations

JA Vallejos et al. 